\title{
Carboxylesterase 2 and Intestine Transporters Contribute to the Low Bioavailability of Allisartan, a Prodrug of Exp3174 for Hypertension Treatment in Humans ${ }^{\mathrm{S}}$
}

\author{
Xiuli Li, Jingchao Sun, Zitao Guo, Dafang Zhong, and Xiaoyan Chen \\ Shanghai Institute of Materia Medica, Chinese Academy of Sciences, Shanghai, China (X.L., Z.G., D.Z., X.C.); and Shenzhen \\ Salubris Pharmaceutical, Guangdong, China (J.S.)
}

Received October 24, 2018; accepted May 8, 2019

\begin{abstract}
Exp3174 is an active metabolite of losartan for the treatment of hypertension. Allisartan (ALS3) is a marketed ester prodrug of Exp3174 to reduce bioavailability variation of losartan in China. However, ALS3 exhibited a lower oral absorption than losartan in humans. In this study, the enzymes and transporters involved in ALS3 and Exp3174 disposition were investigated to clarify the mechanisms. ALS3 underwent extensive hydrolysis to Exp3174 in S9 of Caco-2 cells, human intestine microsomes (HIM), recombinant carboxylesterase (rCES) 1, and rCES2. ALS3 exhibited similar affinity in HIM and rCES2 with $K_{\mathrm{m}}$ values of 6.92 and $6.77 \mu \mathrm{M}$, respectively, indicating that ALS3 is mainly hydrolyzed to Exp3174 in human intestine by CES2. Transport assays of ALS3 and Exp3174 suggested that ALS3 and Exp3174 are substrates of P-glycoprotein, breast cancer resistance protein, and multidrug resistance protein 2 with poor permeability.
\end{abstract}

Organic anion-transporting polypeptide 2B1 showed higher affinity and clearance toward ALS3 $\left(K_{\mathrm{m}} 0.75 \mu \mathrm{M}\right.$ and intrinsic clearance $215 \mu \mathrm{l} / \mathrm{min} / \mathrm{mg})$ than those of Exp3174 $\left(K_{\mathrm{m}} 7.85 \mu \mathrm{M}\right.$ and intrinsic clearance $16.1 \mu \mathrm{l} / \mathrm{min} / \mathrm{mg}$ ), indicating that ALS3 is preferred to be uptaken into intestinal epithelia. Hydrolysis of ALS3 was increased from approximately $30 \%$ to $55 \%$ in CES2-transfected human embryonic kidney 293-OATP2B1 cells, indicating the possible interplay between OATP2B1 and CES2. The influx and efflux of ALS3 across Caco-2 cells increased the potential of ALS3 hydrolysis to Exp3174, and the produced Exp3174 was rapidly pumped out, which led to undetectable ALS3 and Exp3174 in basolateral (receiver) side in Caco2 cells. Overall, our study provided supportive evidences that the interplay between CES2 and transporters in intestine contributes to the low bioavailability of ALS3 in humans.

\section{Introduction}

Hypertension, a common clinical problem worldwide, is one of the largest contributors to global mortality (Rubio-Guerra and DuranSalgado, 2015). Hypertension has a high global prevalence of $16.0 \%-$ $36.9 \%$ and shows a trend toward younger ages (Poulter et al., 2015). First-line medications for hypertension include angiotensin-converting enzyme inhibitors, angiotensin receptor agonists, thiazide diuretics, and calcium channel blockers, which may be used alone or in combination to effectively control blood pressure. Losartan is the first orally available selective angiotensin II type 1 receptor antagonist, and it is metabolized by cytochrome P450 2C9 (CYP2C9) and CYP3A4 in humans to the active metabolite Exp3174 to lower blood pressure (Lo et al., 1995; Stearns et al., 1995; Yun et al., 1995). However, losartan exhibited variable oral bioavailability $(12.1 \%-66.6 \%)$ in humans, which may be

This work was supported by the Young Science Foundation of the National Natural Science Foundation of China [Grant 81703602] and Strategic Priority Research Program of the Chinese Academy of Sciences [XDA 12050306].

https://doi.org/10.1124/dmd.118.085092.

S This article has supplemental material available at dmd.aspetjournals.org. associated with the first-pass metabolism and polymorphism of CYP2C9 (Lo et al., 1995; Yasar et al., 2001, 2002; Yang et al., 2011).

To overcome the low and variation in bioavailability of losartan, allisartan (ALS3, Fig. 1), an ester prodrug of Exp3174, was developed in China (Wu et al., 2009; Li et al., 2015). However, the exposure of Exp3174 in humans after an oral dose of $240 \mathrm{mg}$ ALS3 is comparable with that of $100 \mathrm{mg}$ losartan (4.43 hour $\times \mathrm{mg} / \mathrm{l}$ vs. 4.76 hour $\times \mathrm{mg} / \mathrm{l}$, respectively), which indicates that ALS3 shows an even lower oral bioavailability than losartan (data from the label of Allisartan Isoproxil tablets)

Low bioavailability of orally administered drugs is often associated with poor absorption and/or extensive first-pass metabolism (Nauli and Nauli, 2013). The intestine is usually the first barrier to limit drug absorption or metabolize drugs (Nauli and Nauli, 2013). Drugs with low permeability access the intestinal epithelia cells with difficulty, leading to low bioavailability, except with the facilitation of uptake transporters in intestine. Drugs with high permeability such as digoxin still cross the intestinal epithelia cells with difficulty due to the efflux transporter P-glycoprotein (P-gp) (Wu and Benet, 2005). Apart from efflux transporters, intestinal enzymes such as CYP3A4 and UDP-glucuronosyltransferases are involved in drug first-pass metabolism, leading to the

ABBREVIATIONS: AADAC, arylacetamide deacetylase; ALS3, allisartan; BCA, bicinchoninic acid; BCRP, breast cancer resistance protein; BNPP, bis-p-nitrophenyl phosphate; BSA, bovine serum albumin; CES, carboxylesterase; ER, efflux ratio; HBSS, Hanks' balanced salt buffer; HEK, human embryonic kidney; HIM, human intestine microsomes; LC-MS/MS, liquid chromatography-tandem mass spectrometry; MDCK, Madin-Darby canine kidney; MDR1, multi-drug resistance; MRP2, multidrug resistance protein 2; MTX, methotrexate; OATP, organic anion-transporting polypeptide; P-gp, P-glycoprotein; rAADAC, recombinant AADAC; rCES, recombinant CES; RT-PCR, reverse-transcription polymerase chain reaction. 


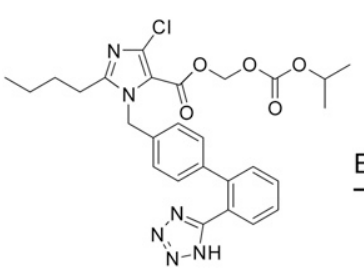

ALS3

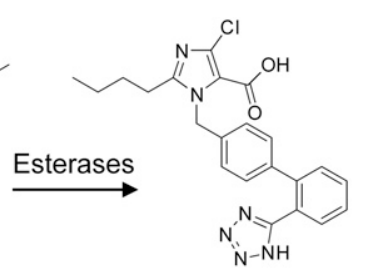

Exp3174

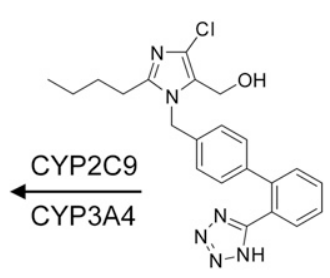

Losartan
Fig. 1. Chemical structures of allisartan (ALS3), Exp3174, and losartan. decreased bioavailability (Komura and Iwaki, 2011). The interplay between metabolism enzymes and efflux transporters in intestine plays important roles in limiting drug bioavailability, such as sirolimus, which is the cosubstrate of CYP3A4 and P-gp (Benet et al., 2003, 2004; Cummins et al., 2003), and ME3229, cosubstrate of breast cancer resistance protein (BCRP) and carboxylesterase (CES) (Kondo et al., 2005). The plasma exposure of sirolimus was approximately nine times greater when sirolimus was coadministered with ketoconazole, an inhibitor of CYP3A4 and P-gp to the healthy subjects (Zimmerman, 2004). In addition to CYP3A4, CES2 and arylacetamide deacetylase (AADAC) are also highly expressed in small intestine and contribute to the hydrolysis of many drugs, including flutamide, phenacetin, and prasugrel (Watanabe et al., 2009, 2010; Kurokawa et al., 2016). ALS3 is designed to hydrolyze to Exp3174 by esterase; however, the esterase isozymes contributing to ALS3 hydrolysis in which tissues are still in question. The reason for the low bioavailability of ALS3 in humans remains unclear.

In vitro cultured Caco- 2 cells preserve the expression of CYP enzymes and transporters, including P-gp, BCRP, and multidrug resistance protein 2 (MRP2) in intestine, and are routinely used for drug permeability and transport studies (Imai et al., 2005; Lin et al., 2011). Different from esterase in small intestine, CES1 is abundantly expressed in Caco-2 cells, which is responsible for temocapril hydrolysis during transport in Caco-2 cells (Imai et al., 2005; Ohura et al., 2011). Therefore, Caco- 2 cells are potentially powerful tools to evaluate the transport and hydrolysis of ALS3.

Hence, this study was designed to investigate the involvement of hydrolytic enzymes and transporters in the disposition of ALS3 and Exp3174 by using a variety of recombinant esterases and cell lines to explore the mechanisms under the low oral bioavailability of ALS3 in humans.

\section{Materials and Methods}

Materials. ALS3 (99.4\% purity) and Exp3174 (99.8\% purity) were provided by Shenzhen Salubris Pharmaceutical (Shenzhen, China). Atorvastatin, digitonin, eserine, GF120918, KO-143, MK-571, methotrexate, quercetin, candesartan, bovine serum albumin (BSA), and the bicinchoninic acid (BCA) protein assay kit were purchased from Dalian Meilun Biology Technology (Dalian, China). Loperamide, bis-p-nitrophenylphosphate (BNPP), fenofibrate, phenacetin, procaine, vinblastine, and Hanks' balanced salt buffer (HBSS, pH 7.4) were obtained from Sigma-Aldrich (St. Louis, MO). Dulbecco's modified Eagle's medium, fetal bovine serum, L-glutamine, minimum essential medium nonessential amino acids, penicillin G, streptomycin, Lipofectamine 3000 reagent, and TRIzol were purchased from Invitrogen (Carlsbad, CA). Human intestinal microsomes (HIM) and BioCoat poly-D-lysine-coated 24-well plates were supplied by BD Biosciences (Woburn, MA). Recombinant human CES1 and CES2 were obtained from Cyper (Scotland, UK). Recombinant human AADAC was purchased from CUSABIO Biotech (Wuhan, China). Membrane vesicles expressing P-gp, BCRP, or MRP2 were provided by Genomembrane (Yokohama, Japan). Human CES2 natural open reading frame (ORF) mammalian expression plasmid was purchased from Sino Biologic (Beijing, China). The Caco-2 cell line was obtained from American Type Culture Collection (Rockville, MD). HEK293 cells individually transfected with organic anion-transporting polypeptide (OATP) 2B1 and vector control (mock-transfected cells) were established at HD Biosciences (Shanghai, China), and their Western blot results are shown in Supplemental Fig. 1. HEK293-OATP1A2 cells and Madin-Darby canine kidney (MDCK) cells overexpressing P-gp (MDCK-MDR1) and BCRP (MDCK-BCRP) cell lines were supplied by H. Zhang (College of Pharmaceutical Science, Soochow University, Soochow, China). The MDCK cell line transfected with MRP2 (MDCK-MRP2) was provided by Z. Zuo (Chinese University of Hong Kong, Hong Kong, China) (Li et al., 2012). All other solvents and reagents were of either high-performance liquid chromatography or analytical grade.

Cell Culture. All cells were maintained in Dulbecco's modified Eagle's medium supplemented with $10 \%$ fetal bovine serum, $2 \mathrm{mM}$ L-glutamine, $100 \mathrm{U} / \mathrm{ml}$ penicillin $\mathrm{G}, 100 \mu \mathrm{g} / \mathrm{ml}$ streptomycin, and $1 \%$ minimum essential medium nonessential amino acids at $37^{\circ} \mathrm{C}$ in a humidified $5 \% \mathrm{CO}_{2}$ atmosphere. Caco-2 cells and MDCK cells were seeded at a density of $2 \times 10^{5}$ cells $/ \mathrm{cm}^{2}$ on a polycarbonate membrane on Transwell inserts (Millipore, Billerica, MA) and incubated for 21 and 5 days to form monolayers before bidirectional transepithelial transport studies, respectively. HEK293 cells were seeded into BioCoat poly-D-lysine-coated 24-well plates (BD Biosciences) at a density of $2 \times 10^{5}$ cells/well, and the uptake studies were conducted 2 days after seeding.

Bidirectional Transepithelial Transport. Prior to the study, Caco-2 cells and MDCK cells were washed twice with prewarmed HBSS and incubated with fresh HBSS at $37^{\circ} \mathrm{C}$ for 30 minutes. HBSS- $0.5 \%$ BSA containing ALS3 or Exp3174 $(2-50 \mu \mathrm{M})$ was then added to the apical $(300 \mu \mathrm{l})$ or basolateral $(1300 \mu \mathrm{l})$ chamber, whereas drug-free HBSS- $0.5 \%$ BSA was added to the other side. Aliquots of $150 \mu \mathrm{l}$ were collected from the donor side within 5 minutes to work as $\mathrm{C}_{0}$ samples. After the cells were incubated at $37^{\circ} \mathrm{C}$ for designed time with gentle shaking, aliquots of $150 \mu \mathrm{l}$ were collected from both chambers to work as $\mathrm{C}_{\mathrm{t}}$ samples. The cell monolayers were washed twice with prewarmed HBSS and lysed with $200 \mu$ l acetonitrile. ALS3 in HBSS-0.5\% BSA without Caco-2 cells was used as a negative control to evaluate the stability of ALS3 in the matrix. Samples were stored at $-70^{\circ} \mathrm{C}$ until analysis by liquid chromatography-tandem mass spectrometry (LC-MS/MS).

In the inhibition study, cell monolayers were preincubated with HBSScontaining inhibitors (10 $\mu$ M GF120918, $10 \mu \mathrm{M} \mathrm{KO}-143$, and $100 \mu$ M quercetin) for 30 minutes prior to the assay. Inhibitors were added to both chambers to allow for the maximal inhibition on transporters during drug transport.

Membrane Vesicular Transport. The transport of Exp3174 was evaluated in human P-gp-, BCRP-, and MRP2-expressing membrane vesicles using the filtration method based on the manufacturer's protocols with slight modifications. In brief, membrane vesicles (50 $\mu \mathrm{g}$ protein) and test compounds ( 2 and $10 \mu \mathrm{M}$ Exp3174) were incubated with ATP or AMP $(4 \mathrm{mM})$ in reaction buffer containing $50 \mathrm{mM}$ 4-morpholinepropanesulfonic acid-Tris, $70 \mathrm{mM} \mathrm{KCl}$, and $7.5 \mathrm{mM} \mathrm{MgCl}{ }_{2}$ at $37^{\circ} \mathrm{C}$ for 10 minutes. In the MRP2 incubation system, glutathione $(2 \mathrm{mM})$ was added to the reaction buffer to stimulate transport. Vinblastine at $1 \mu \mathrm{M}$ and methotrexate (MTX) at 100 and $5 \mu \mathrm{M}$ were used as probe substrates of P-gp, BCRP, and MRP2, respectively. Inhibitors GF120918 at $10 \mu \mathrm{M}, \mathrm{KO}-143$ at $10 \mu \mathrm{M}$, and MK-571 at $20 \mu \mathrm{M}$ were preincubated with P-gp, BCRP, or MRP2 for 5 minutes to inhibit the transport ability of vesicles, respectively. Transport was terminated by the addition of $200 \mu \mathrm{l}$ ice-cold wash buffer $(40 \mathrm{mM}$ 4-morpholinepropanesulfonic acid-Tris and $70 \mathrm{mM} \mathrm{KCl}$ ), and the incubation mix was quickly transferred to a Millipore 96-well glass-filter plate (Millipore) to wash five times with chilled wash buffer. Compounds in the vesicles were released by the addition of $150 \mu 1$ methanol-water $(70: 30, v / v)$. Samples were stored at $-70^{\circ} \mathrm{C}$ until analysis by LC-MS/MS.

Preparation of S9 of Caco-2 Cells. The S9 of Caco-2 cells was prepared with slight modifications from literature (Ohura et al., 2011). Briefly, Caco-2 cells were grown on a $150-\mathrm{mm}$ dish for 21 days at $37^{\circ} \mathrm{C}$, and the media was renewed 1 day 
before the experiment. Caco- 2 cells were rinsed twice with ice-cold HBSS and then detached with a spatula. The harvested cells were suspended in ice-cold buffer (292 mM sucrose, $1 \mathrm{mM}$ EDTA, and $50 \mathrm{mM}$ Tris, $\mathrm{pH}$ 7.4) and then homogenized at $4^{\circ} \mathrm{C}$ to obtain homogenates. Half volume of homogenates was centrifuged at $9000 \mathrm{~g}$ for 20 minutes at $4^{\circ} \mathrm{C}$ to separate the $\mathrm{S} 9$ fraction. The protein concentration of $\mathrm{S} 9$ of Caco-2 cells was determined using a BCA assay kit. Prior to the hydrolysis study, S9 was adjusted to $0.5 \mathrm{mg} / \mathrm{ml}$ with $100 \mathrm{mM}$ PBS (containing $3.2 \mathrm{mM} \mathrm{MgCl}$, $\mathrm{pH}$ 7.4).

Hydrolysis Experiment. Hydrolysis of ALS3 was investigated in different enzyme sources, including S9 of Caco-2 cells, HIM, recombinant CES1 (rCES1), rCES2, and recombinant AADAC (rAADAC). ALS3 was incubated with various enzyme sources in $0.2 \mathrm{ml} 100 \mathrm{mM}$ PBS (containing $3.2 \mathrm{mM} \mathrm{MgCl}_{2}, \mathrm{pH} 7.4$ ) at $37^{\circ} \mathrm{C}$ for the designed time with gentle shaking. Control incubations were conducted in the absence of enzyme sources. In the inhibition study, inhibitors (500 $\mu \mathrm{M}$ BNPP, $20 \mu \mathrm{M}$ digitonin, $20 \mu \mathrm{M}$ loperamide, and $20 \mu \mathrm{M}$ eserine) were preincubated with enzyme sources 5 minutes prior to the addition of ALS3. The final concentration of organic reagent was $<0.5 \%$ in the incubation mixture. Incubation was stopped by the addition of $0.2 \mathrm{ml}$ ice-cold acetonitrile at the designed time point. Samples were maintained at $-70^{\circ} \mathrm{C}$ until analysis by LC-MS/MS.

Uptake Studies in OATP1A2- and OATP2B1-Expressing HEK293 Cells. Prior to the assay, cells were rinsed three times with prewarmed $\operatorname{HBSS}\left(37^{\circ} \mathrm{C}\right)$ and equilibrated in HBSS for 10 minutes. Uptake studies were initiated by the addition of HBSS containing Exp3174 or ALS3 and were terminated at the designed time after removing the transport buffer. Cells were washed with ice-cold HBSS three times and lysed with deionized water $(200 \mu \mathrm{l})$ by three freeze-thaw cycles. The protein content of the cell lysate was determined using the BCA protein assay kit. The concentrations of Exp3174 or ALS3 in the cell lysate were determined by LC-MS/MS.

Transient Transfection of CES2 into Caco-2 Cells and HEK293OATP2B1Cells. Transient transfection of CES2 using Lipofectamine 3000 was performed, according to the manufacturer's protocol. Briefly, Caco-2 cells and HEK293-OATP2B1 cells were seeded on 24-well cell culture-treated plates at a density of $2 \times 10^{5}$ cells/well to ensure $70 \%-90 \%$ confluency at transfection on the next day. The ratios of DNA to Lipofectamine 3000 and DNA to P3000 reagent were 2:3 $(w / v)$ and 1:2 $(w / v)$, respectively. A total of $500 \mathrm{ng}$ plasmid DNA was transferred to each well of the 24-well plate. The hydrolysis of ALS3 and the extraction of RNA in transfected Caco-2 cells and HEK293-OATP2B1 cells were performed 48 hours after transfection.

Reverse-Transcription Polymerase Chain Reaction. Total RNA was extracted from the transiently transfected Caco-2 cells and HEK293OATP2B1 cells using TRIzol reagent (Invitrogen). Total RNA was reverse transcribed into cDNA using the PrimeScript RT reagent kit (Takara Bio, Otsu, Japan). Polymerase chain reaction was performed with SYBR Green Premix Ex Taq TM kit (Takara Bio), and the CES2 expression was normalized to $\beta$-actin. Forward primer and reverse primer for CES1 were
GGTCGGAATTAACAAGCA and TCCTAAGTATTTCTCAGTGGC, respectively. For CES2, the forward primer and reverse primer were GCTGAGGGAGGAGTACATTG and GGAGTGCAGGGATCACAA, respectively. For $\beta$-actin, the forward primer and reverse primer were GGACTTCGAGCAAGAGATGG and AGCACTGTGTTGGCGTACAG, respectively.

Hydrolysis of ALS3 in CES2-Transfected Caco-2 Cells and HEK293OATP2B1 Cells. Prior to the assay, cells were rinsed three times with prewarmed HBSS $\left(37^{\circ} \mathrm{C}\right)$ and equilibrated in HBSS for 10 minutes. For ALS3 hydrolysis in CES2-transfected or CES2-nontransfected Caco-2 cells, cells were pretreated with fenofibrate $(20 \mu \mathrm{M})$ or digitonin $(20$ and $50 \mu \mathrm{M})$ for 1 hour to inhibit the activity of CES1, and then ALS3 at 1 and $10 \mu \mathrm{M}$ was incubated with cells for 5 minutes in the presence or absence of inhibitors. For ALS3 hydrolysis in CES2transfected or CES2-nontransfected HEK293-OATP2B1 cells, ALS3 at 1 and $10 \mu \mathrm{M}$ was incubated with cells for 1 minute at $37^{\circ} \mathrm{C}$. After hydrolysis, cells were washed with ice-cold HBSS three times and lysed with $200 \mu$ l acetonitrile-water $(70: 30, v / v)$. The concentrations of Exp3174 and ALS3 in the cell lysate were determined by LC-MS/MS.

LC-MS/MS Analysis. The concentration of analytes was determined using a Shimadzu LC-30AD high-performance liquid chromatography system (Kyoto, Japan) and a Triple Quad 5500 mass spectrometer (AB Sciex, Concord, Ontario, Canada) equipped with a TurboIonSpray ion source. Chromatographic separation was achieved on a YMC-Triart $\mathrm{C}_{18}$ column $(50 \times 2.0 \mathrm{~mm}$ i.d., $5 \mu \mathrm{m}$; YMC, Kyoto, Japan) at $40^{\circ} \mathrm{C}$ under gradient conditions at a flow rate of $0.6 \mathrm{ml} / \mathrm{min}$. For ALS3, Exp3174, and vinblastine determination, the initial mobile phase was 30\% acetonitrile (solvent A) and 70\% $5 \mathrm{mM}$ ammonium acetate-formic acid (100:0.1, $v / v$, solvent B) for 0.1 minute, followed by a linear increase to $95 \% \mathrm{~A}$ over 0.8 minute, which was then maintained for 0.8 minute. The column was equilibrated with the initial mobile phase for 0.7 minute, and the total run time was 2.4 minutes. For MTX determination, the initial mobile phase was $5 \%$ acetonitrile (solvent A) and 95\% $5 \mathrm{mM}$ ammonium acetate-formic acid (100:0.1, $v / v$, solvent B) for 0.1 minute, followed by a linear increase to $30 \% \mathrm{~A}$ over 1.0 minute, which was then maintained for 0.9 minute. The column was equilibrated with the initial mobile phase for 1.0 minute, and the total run time was 3.0 minute. For hydrolysis metabolites of phenacetin and procaine determination, the initial mobile phase was 5\% methanol (solvent A) and $95 \% 5 \mathrm{mM}$ ammonium acetate-formic acid (100:0.1, $v / v$, solvent B) for 0.5 minute, followed by a linear increase to $85 \% \mathrm{~A}$ over 0.4 minute, which was then maintained for 0.8 minute. The column was equilibrated with the initial mobile phase for 0.7 minute, and the total run time was 2.4 minutes. For hydrolysis metabolites of fenofibrate determination, the initial mobile phase was $50 \%$ methanol (solvent A) and 50\% $5 \mathrm{mM}$ ammonium acetate-formic acid (100:0.1, $v / v$, solvent B) for 0.8 minute, followed by a linear increase to $85 \%$ A over 0.1 minute, which was then maintained for 1.0 minute. The column was equilibrated with the initial mobile phase for 1.1 minutes, and the total run time was 3.0 minutes.

The mass spectrometer was operated in the positive mode with an ion spray voltage of $5500 \mathrm{~V}$ and a source temperature of $550^{\circ} \mathrm{C}$. The nebulizer gas, heater

TABLE 1

Bidirectional transepithelial transport of Exp3174 in Caco-2 cells

The subscripts A, B, and C represent apical side, basolateral side, and cell lysate, respectively. Data are shown as the mean \pm S.D. $(\mathrm{n}=3)$.

\begin{tabular}{|c|c|c|c|c|}
\hline & \multirow{2}{*}{$\frac{\text { Exp3174 }}{(\mathrm{nM})}$} & \multicolumn{3}{|c|}{ Exp3174 Dosing Concentration } \\
\hline & & $2 \mu \mathrm{M}$ & $10 \mu \mathrm{M}$ & $50 \mu \mathrm{M}$ \\
\hline \multirow[t]{5}{*}{ A to $B$} & $\mathrm{C}_{0, \mathrm{~A}}$ & $1937 \pm 107$ & $9267 \pm 286$ & $44,367 \pm 2212$ \\
\hline & $\mathrm{C}_{2 \mathrm{~h}, \mathrm{~A}}$ & $1953 \pm 59$ & $9690 \pm 282$ & $45,033 \pm 2363$ \\
\hline & $\mathrm{C}_{2 \mathrm{~h}, \mathrm{~B}}$ & BQL & BQL & $1.43 \pm 0.06$ \\
\hline & $\mathrm{C}_{2 \mathrm{~h}, \mathrm{C}}$ & $2.32 \pm 0.21$ & $10.0 \pm 0.8$ & $49.0 \pm 0.5$ \\
\hline & $\mathrm{P}_{\text {app, A to } \mathrm{B}}\left(\times 10^{-8} \mathrm{~cm} / \mathrm{s}\right)$ & $2.50 \pm 0.1^{a}$ & $1.64 \pm 0.0^{a}$ & $1.56 \pm 0.0$ \\
\hline \multirow[t]{6}{*}{$\mathrm{B}$ to $\mathrm{A}$} & $\mathrm{C}_{0, \mathrm{~B}}$ & $1973 \pm 105$ & $9620 \pm 358$ & $44,733 \pm 1002$ \\
\hline & $\mathrm{C}_{2 \mathrm{~h}, \mathrm{~B}}$ & $1863 \pm 97$ & $9723 \pm 195$ & $45,367 \pm 2593$ \\
\hline & $\mathrm{C}_{2 \mathrm{~h}, \mathrm{~A}}$ & $7.97 \pm 0.39$ & $38.3 \pm 4.3$ & $235 \pm 20$ \\
\hline & $\mathrm{C}_{2 \mathrm{~h}, \mathrm{C}}$ & $19.3 \pm 0.2$ & $100 \pm 14$ & $328 \pm 11$ \\
\hline & $\mathrm{P}_{\mathrm{app}, \mathrm{B} \text { to } \mathrm{A}}\left(\times 10^{-8} \mathrm{~cm} / \mathrm{s}\right)$ & $25.6 \pm 2.1$ & $25.1 \pm 2.6$ & $33.2 \pm 3.6$ \\
\hline & ER & $10.2^{a}$ & $15.3^{a}$ & 21.2 \\
\hline
\end{tabular}

${ }^{a} \mathrm{P}_{\text {app }}$ was calculated based on the lower limit of quantitation $(0.2 \mathrm{nM})$, as the concentration of Exp3174 in receiver side was below the quantitation limit (BQL), and thereby the calculated ER values were only for reference. 
TABLE 2

Inhibition on bidirectional transepithelial transport of Exp3174 at $50 \mu \mathrm{M}$ in Caco-2 cells

The concentrations of GF120918, KO-143, and quercetin were 10, 10, and $100 \mu M$, respectively. Data are shown as the mean $\pm S . D .(\mathrm{n}=3)$.

\begin{tabular}{lccr}
\hline & \multicolumn{2}{c}{ Papp $\left(\times 10^{-8} \mathrm{~cm} / \mathrm{s}\right)$} & \\
\cline { 2 - 3 } & \multicolumn{1}{c}{ A to B } & ER \\
\hline Exp3174 & $1.65 \pm 0.57$ & $43.5 \pm 5.1$ & 30.0 \\
Exp3174 + GF120918 & $1.29 \pm 0.41$ & $23.3 \pm 5.4$ & 21.5 \\
Exp3174 + KO-143 & $5.22 \pm 3.19$ & $18.5 \pm 2.3$ & 3.5 \\
Exp3174 + quercetin & $3.84 \pm 1.05$ & $12.5 \pm 3.4$ & 3.6 \\
\hline
\end{tabular}

gas, collision gas, and curtain gas were set at 50, 50, 9, and 30 psi, respectively. The declustering potential was maintained at $80 \mathrm{~V}$. The mass transitions for multiple reaction monitoring were $m / z 553.3 \rightarrow m / z 419.1$ for ALS3 (CE $19 \mathrm{~V}$ ), $\mathrm{m} / \mathrm{z}$ 437.2 $\rightarrow m / z 235.0$ for Exp3174 (CE $22 \mathrm{~V}$ ), $\mathrm{m} / z$ 441.2 $\rightarrow m / z 263.2$ for candesartan (internal standard for ALS3 and Exp3174, CE 16 V), $m / z, 455.4 \rightarrow m / z, 308.1$ for MTX (CE $28 \mathrm{~V}), \mathrm{m} / \mathrm{z} 811.5 \rightarrow \mathrm{m} / \mathrm{z} 224$ for vinblastine (CE $46 \mathrm{~V}$ ), $\mathrm{m} / \mathrm{z}, 138.1 \rightarrow \mathrm{m} / \mathrm{z}$ 110.1 for phenacetin hydrolysis metabolite (CE $21 \mathrm{~V}$ ), $\mathrm{m} / z, 138.1 \rightarrow \mathrm{m} / \mathrm{z}, 120.0$ for procaine hydrolysis metabolite $(\mathrm{CE} 17 \mathrm{~V})$, and $\mathrm{m} / \mathrm{z} 319.1 \rightarrow \mathrm{m} / \mathrm{z} 233.0$ for fenofibrate hydrolysis metabolite (CE $30 \mathrm{~V})$.

Data Analysis. The permeability coefficients $\left(\mathrm{P}_{\mathrm{app}}, \mathrm{cm} / \mathrm{s}\right)$ of ALS3 and Exp3174 and the efflux ratio (ER) were calculated according to eqs. 1 and 2 , respectively.

$$
\begin{gathered}
\mathrm{P}_{\text {app }}=\mathrm{C}_{\mathrm{t}, \text { receiver }} \times \mathrm{V}_{\text {receiver }} /\left(\mathrm{S} \times \mathrm{C}_{0, \text { donor }} \times t\right) \\
\mathrm{ER}=\mathrm{P}_{\text {app }, \text { B to A }} / \mathrm{P}_{\text {app }, \text { A to B }}
\end{gathered}
$$

where $\mathrm{C}_{\mathrm{t}, \text { receiver }}$ (nanomolars) is the concentration of ALS3 or Exp3174 in the receiver side at 2 hours, $V_{\text {receiver }}$ is the volume in the receiver side ( $150 \mu l$ for apical chamber, $1150 \mu \mathrm{l}$ for basolateral chamber), $\mathrm{S}$ is the surface area of the Transwell inserts $\left(0.33 \mathrm{~cm}^{2}\right), \mathrm{C}_{0 \text {,donor }}$ (nanomolars) is the initial concentration of ALS3 or Exp3174 in the donor side, and $t$ is the incubation time (7200 seconds).

GraphPad Prism (version 6.01; GraphPad Software, San Diego, CA) was used to calculate the kinetic parameters. All data are expressed as the mean \pm S.D.

Hydrolysis or Uptake Kinetics. The ALS3 hydrolysis rate was calculated based on the concentration of Exp3174 and the protein concentration of the incubation system. The ALS3 or Exp3174 uptake rate was normalized to the protein concentration of the cell lysate, and the transporter-mediated uptake was corrected by subtracting the accumulation in mock-transfected HEK293 cells from that of transporter-expressing HEK293 cells. For the kinetic parameter calculations, data were fitted to the Michaelis-Menten eq. 3 or allosteric sigmoidal modeling (eq. 4), according to the Eadie-Hofstee plots.

$$
\begin{gathered}
V=V_{\max } \times S /\left(K_{m}+S\right) \\
V=V_{\max } \times S^{h} /\left(K_{m}{ }^{h}+S^{h}\right)
\end{gathered}
$$

where $V(\mathrm{pmol} / \mathrm{min} / \mathrm{mg})$ is the velocity of substrate hydrolysis or uptake, $S$ (micromolars) is the substrate concentration, $K_{\mathrm{m}}$ (micromolars) is the substrate concentration at half-maximal rate $\left(V_{\max }\right)$, and $h$ is the Hill slope. Intrinsic clearance is calculated as $V_{\max } / K_{\mathrm{m}}$ for both models.

SPSS software (version 16.0 for Windows; SPSS, Chicago, IL) was used to determine significant differences with two-tailed paired Student's $t$ test. $P$ values of $<0.05$ were regarded as statistically significant.

\section{Results}

Bidirectional Transepithelial Transport of Exp3174 in Caco-2 Cells. In the preliminary transport of Exp3174 at $50 \mu \mathrm{M}$ in Caco-2 cells, the concentration of Exp3174 in the basolateral receiver side was approximately linearly increased over 2 hours (Supplemental Fig. 2). Considering the low permeability of Exp3174 and the detection sensitivity, permeability of Exp3174 in Caco- 2 cells was evaluated

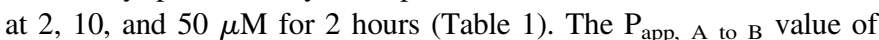
Exp3174 was approximately $10^{-8} \mathrm{~cm} / \mathrm{s}$, indicating that Exp3174 is a

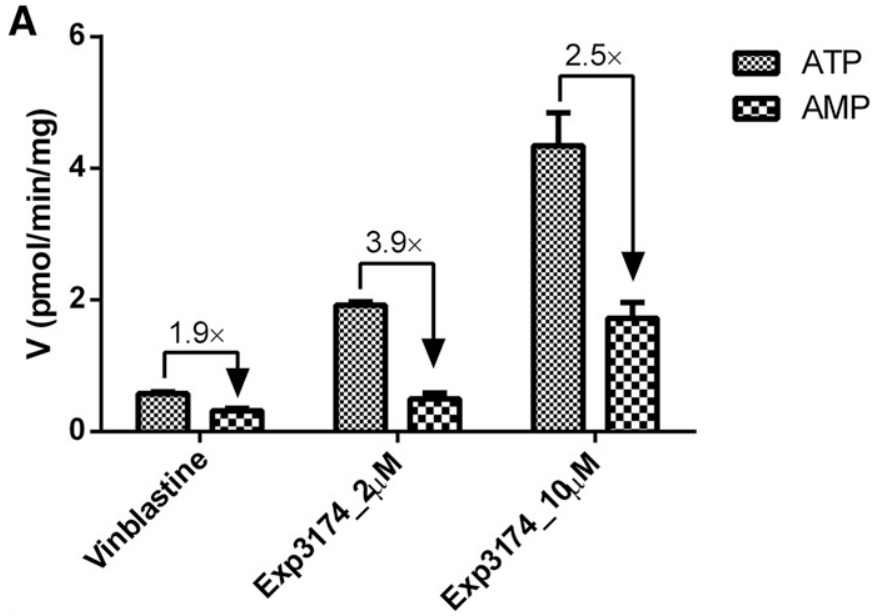

B
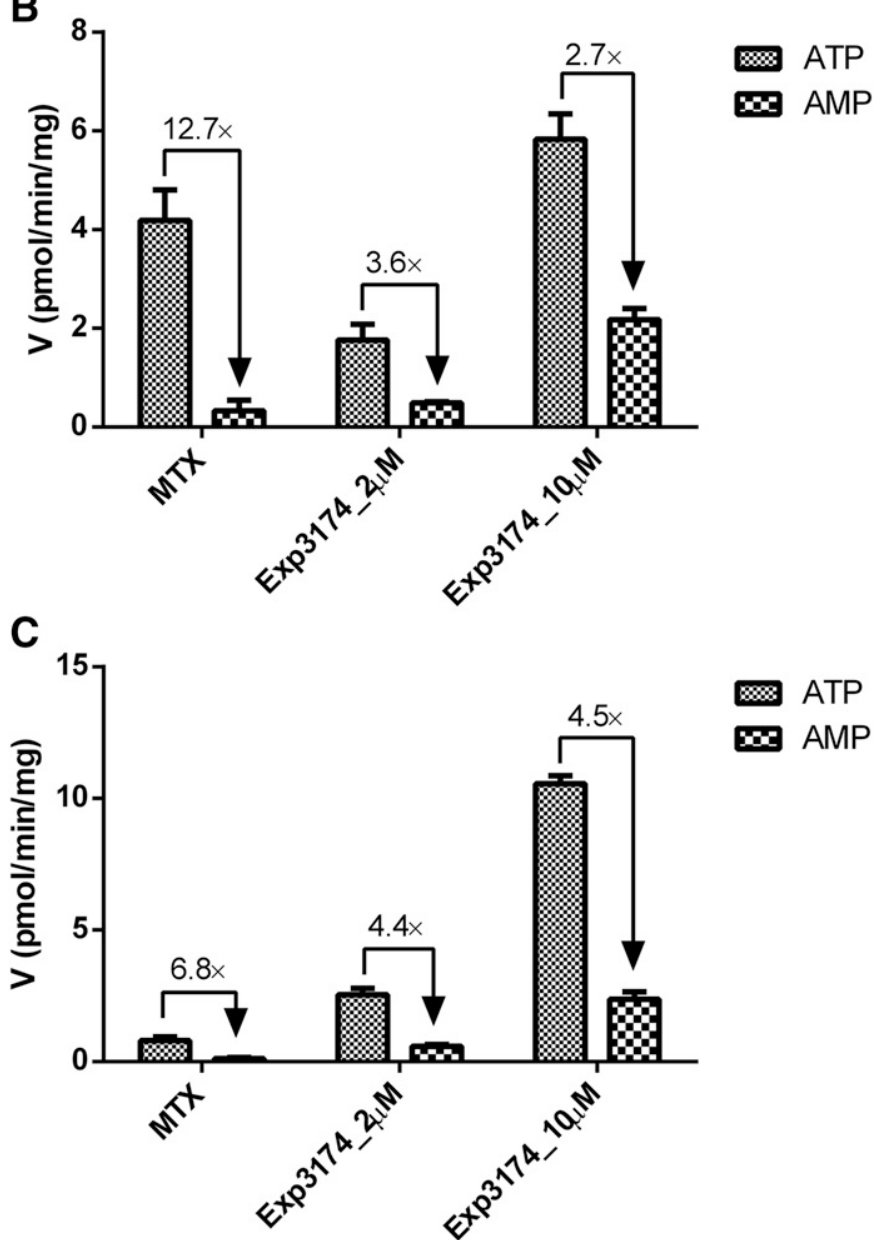

Fig. 2. Transport of Exp3174 by P-gp (A), BCRP (B), and MRP2 (C). Vinblastine at $1 \mu \mathrm{M}$ was used as the positive control of P-gp, and MTX at 100 and $5 \mu \mathrm{M}$ was used as the positive control of BCRP and MRP2, respectively. Positive controls and Exp3174 at 2 and $10 \mu \mathrm{M}$ were incubated with transporter-expressing vesicles in the presence of ATP or AMP with or without inhibitors at $37^{\circ} \mathrm{C}$ for 10 minutes. Data are shown as the mean \pm S.D. $(n=3)$.

low permeability compound. The $\mathrm{P}_{\mathrm{app}}$, B to A of Exp3174 (approximately $10^{-7} \mathrm{~cm} / \mathrm{s}$ ) was much higher than the $P_{\text {app, }}$ A to $B$ with ER values over 2, suggesting that Exp3174 is a substrate of efflux transporters in Caco-2 cells. The known inhibitors GF120918, KO-143, and quercetin all markedly reduced the accumulation of Exp3174 in the apical (receiver) side, and ER values were reduced from 30 to 21.5, 3.5, and 
TABLE 3

Bidirectional transepithelial transport of ALS3 in Caco-2 cells

\begin{tabular}{|c|c|c|c|c|c|c|c|}
\hline \multirow{2}{*}{ Transport } & & \multicolumn{2}{|c|}{$\mathrm{ALS} 3$ at $2 \mu \mathrm{M}$} & \multicolumn{2}{|c|}{ ALS3 at $10 \mu \mathrm{M}$} & \multicolumn{2}{|c|}{ ALS3 at $50 \mu \mathrm{M}$} \\
\hline & & ALS3 (nM) & $\operatorname{Exp} 3174(\mathrm{nM})$ & ALS3 (nM) & $\operatorname{Exp} 3174(\mathrm{nM})$ & ALS3 (nM) & Exp3174 (nM) \\
\hline \multirow[t]{4}{*}{$A$ to $B$} & $\mathrm{C}_{0, \mathrm{~A}}$ & $1710 \pm 335$ & $242 \pm 209$ & $9077 \pm 1062$ & $732 \pm 675$ & $45,667 \pm 1266$ & $1517 \pm 121$ \\
\hline & $\mathrm{C}_{2 \mathrm{~h}, \mathrm{~A}}$ & $85.8 \pm 59.1$ & $1670 \pm 66$ & $1997 \pm 119$ & $6723 \pm 169$ & $28,733 \pm 2974$ & $17,000 \pm 1389$ \\
\hline & $\mathrm{C}_{2 \mathrm{~h}, \mathrm{~B}}$ & BQL & BQL & BQL & BQL & $1.34 \pm 0.61$ & $13.6 \pm 1.3$ \\
\hline & $\mathrm{C}_{2 \mathrm{~h}, \mathrm{C}}$ & BQL & $3.85 \pm 0.64$ & $\mathrm{BQL}$ & $24.2 \pm 1.2$ & $3.93 \pm 2.76$ & $288 \pm 18$ \\
\hline \multirow[t]{4}{*}{$\mathrm{B}$ to $\mathrm{A}$} & $\mathrm{C}_{0, \mathrm{~B}}$ & $1833 \pm 110$ & $\mathrm{BQL}$ & $9423 \pm 25$ & $219 \pm 23$ & $47,533 \pm 924$ & $1320 \pm 111$ \\
\hline & $\mathrm{C}_{2 \mathrm{~h}, \mathrm{~B}}$ & $1777 \pm 78$ & $209 \pm 6$ & $6957 \pm 480$ & $842 \pm 63$ & $40,600 \pm 1127$ & $4950 \pm 312$ \\
\hline & $\mathrm{C}_{2 \mathrm{~h}, \mathrm{~A}}$ & $\mathrm{BQL}$ & $162 \pm 10$ & $1.24 \pm 0.24$ & $760 \pm 17$ & $15.2 \pm 9.5$ & $3300 \pm 182$ \\
\hline & $\mathrm{C}_{2 \mathrm{~h}, \mathrm{C}}$ & $0.24 \pm 0.05$ & $30.0 \pm 1.0$ & $1.63 \pm 0.62$ & $120 \pm 12$ & $12.0 \pm 2.5$ & $606 \pm 70$ \\
\hline
\end{tabular}

$\mathrm{BQL}$, below the quantitation limit $(0.2 \mathrm{nM})$.

3.6, respectively (Table 2). The inhibition study revealed that efflux transporters including P-gp, BCRP, and MRP2 may be involved in the efflux of Exp3174 in Caco-2 cells.

Membrane Vesicular Transport of Exp3174 Mediated by P-gp, BCRP, and MRP2. To investigate the efflux mechanisms of Exp3174, the transport of Exp3174 into P-gp-, BCRP-, and MRP2- expressing membrane vesicles was investigated. The ratios of ATP-dependent uptake to nonspecific adsorption (ATP/AMP) of vinblastine for P-gp, MTX for BCRP, and MRP2 were 1.9, 12.7, and 6.8, respectively (Fig. 2), and the ratios were all decreased to approximately 1 in the presence of respective inhibitors (data not shown), indicating that the vesicles could be used for Exp3174 uptake studies. The ratios of ATP/AMP of Exp3174 at 2 and $10 \mu \mathrm{M}$ into P-gp, BCRP, and MRP2 vesicles were all over 2.5 (Fig. 2), and the net uptake rate was inhibited by respective inhibitors (data not shown) consistent with Exp3174 being substrates of P-gp, BCRP, and MRP2.

Bidirectional Transepithelial Transport of ALS3 in Caco-2 Cells. ALS3 is approximately stable in the transport buffer without exposure to Caco- 2 cells in 2 hours, as the remaining percentage of ALS3 in transport buffer (HBSS-0.5\% BSA) was approximately $85 \%-92 \%$. The transport of ALS3 at 2, 10, and $50 \mu \mathrm{M}$ in Caco-2 cells was therefore investigated (Table 3). For transport from apical to basolateral chamber (A to B), ALS3 and Exp3174 in basolateral (receiver) side at 2 hours $\left(\mathrm{C}_{2 \mathrm{~h}, \mathrm{~B}}\right)$ were both hardly detectable, whereas the concentration of Exp3174 in apical (donor) side $\left(\mathrm{C}_{2 \mathrm{~h}, \mathrm{~A}}\right)$ was much higher than that of ALS3 at the 2 and $10 \mu \mathrm{M}$ levels. For transport from basolateral to apical chamber (B to A), Exp3174 was the predominant ALS3-related substance in apical (receiver) side $\left(\mathrm{C}_{2 \mathrm{~h}, \mathrm{~A}}\right)$. Exp3174 was also the major component in cell lysate whenever ALS3 was transported from A to B or from B to A. The unique transport of ALS3 in Caco- 2 cells indicated that ALS3 is hydrolyzed to Exp3174 by enzymes in Caco- 2 cells, and the generated Exp3174 is then transported to the apical side by efflux transporters. The accumulation of Exp3174 in apical side for ALS3 transport from B to A was much lower than that from A to B transport, suggesting that uptake transporters on apical membrane facilitate the transport of ALS3 from apical chamber to Caco-2 cells. The concentration of Exp3174 in apical (receiver) side $\left(\mathrm{C}_{2 \mathrm{~h}, \mathrm{~A}}\right)$ when ALS3 instead of Exp3174 transport from B to A was approximately 14-20 times greater (Tables 1 and 3), indicating that ALS3 aids in Exp3174 across the Caco-2 monolayers, which may be attributed to the better permeability of ALS3 than Exp3174. Due to the biotransformation of ALS3 to Exp3174 during the transepithelial transport in Caco-2 cells, $\mathrm{P}_{\text {app }}$ values of ALS3 were not obtained in this study. It was unclear which transporters were involved in ALS3 transport.

Bidirectional Transepithelial Transport of ALS3 in MDCK Cells. The transport of ALS3 was investigated in function-validated MDCK-MDR1, MDCK-BCRP, and MDCK-MRP2 cells cultured for 5 days (Table 4). Although nearly $50 \%$ of ALS3 at $2 \mu \mathrm{M}$ was hydrolyzed to Exp3174 in MDCK suspension cells in 2 hours at $37^{\circ} \mathrm{C}$, only $10 \%$ of ALS3 in donor side was transformed to Exp3174 after a 2-hour incubation with MDCK cell monolayers (data not shown). ALS3 exhibited a poor permeability with $\mathrm{P}_{\mathrm{app}}$, A to $\mathrm{B}$ values of approximately $10^{-7} \mathrm{~cm} / \mathrm{s}$ in MDCK cells. The $\mathrm{P}_{\mathrm{app}}$, B to A of ALS3 was significantly decreased in the presence of GF120918, KO-143, and quercetin in MDCK-MDR1, MDCK-BCRP, and MDCK-MRP2 cells, leading to the ER values of ALS3 decreasing from 8 to 1.2, 3.6, and 6.7, respectively, indicating that ALS3 is a substrate of P-gp, BCRP, and MRP2.

TABLE 4

Bidirectional transepithelial transport of ALS3 in MDCK cells

Data are shown as the mean \pm S.D. $(\mathrm{n}=3)$.

\begin{tabular}{lllll}
\hline \multirow{2}{*}{ Cell Line } & Dosing Compound & \multicolumn{2}{c}{$\mathrm{P}_{\text {app }}\left(\times 10^{-7} \mathrm{~cm} / \mathrm{s}\right)$} & ER \\
\cline { 3 - 4 } & & A to B & B to A & $7.89 \pm 0.47$ \\
\hline \multirow{2}{*}{ MDCK-MDR1 } & ALS3 & $3.43 \pm 1.81^{a}$ & $27.6 \pm 0.9$ & $1.15 \pm 0.04$ \\
& ALS3 + GF120918 & $4.17 \pm 0.06$ & $4.81 \pm 0.09 * * *$ & $8.09 \pm 0.25$ \\
MDCK-BCRP & ALS3 & $3.22 \pm 0.03^{a}$ & $26.4 \pm 0.9$ & $3.56 \pm 0.39$ \\
& ALS3+KO-143 & $3.29 \pm 0.10^{a}$ & $11.6 \pm 0.7 * * *$ & $7.96 \pm 0.07$ \\
MDCK-MRP2 & ALS3 & $3.33 \pm 0.05^{a}$ & $27.1 \pm 1.1$ & $6.68 \pm 0.64$ \\
& ALS3 + Quercetin & $2.83 \pm 0.00^{a}$ & $19.6 \pm 1.7 *$ & $0.7 \pm 0$ \\
\hline
\end{tabular}

${ }^{a} \mathrm{P}_{\text {app }}$ was calculated based on the lower limit of quantitation, as the concentration of Exp3174 in receiver side was below the quantitation limit $(1.0 \mathrm{nM})$.

$* P<0.05 ; * * P<0.01 ; * * * P<0.001$ vs. control values, respectively. 
A

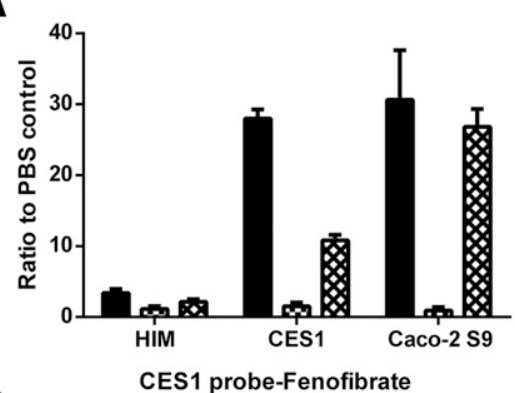

C

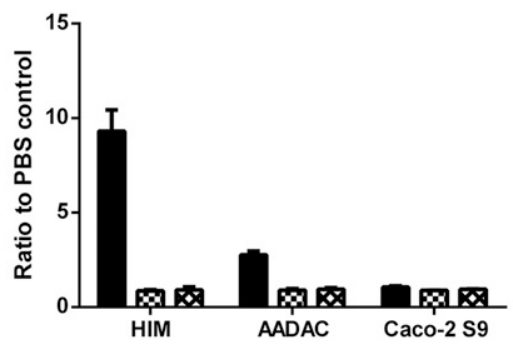

E

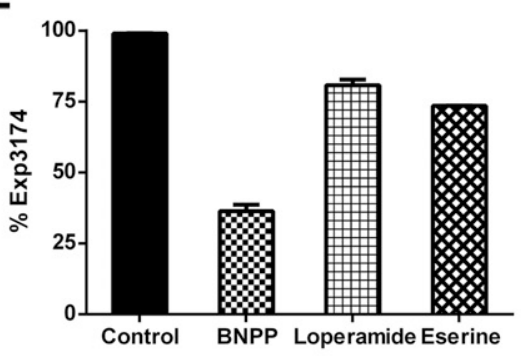

G

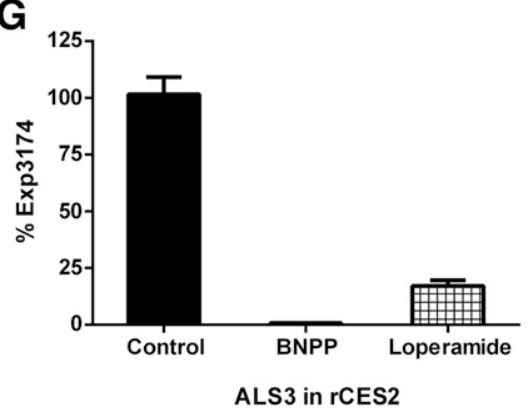

B

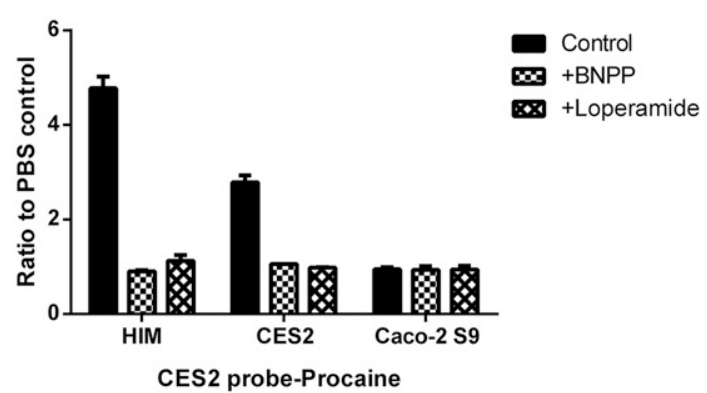

D

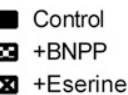

到 +Eserine
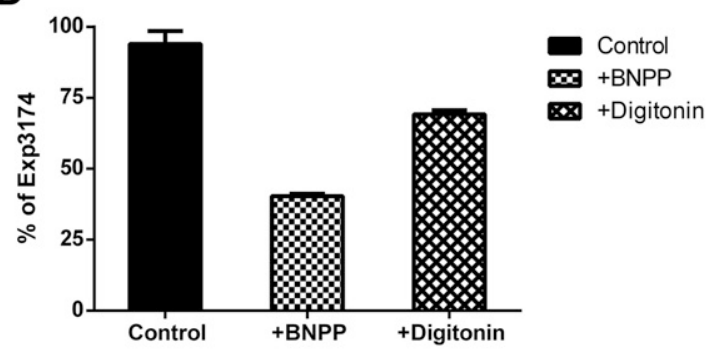

$\mathbf{F}$

ALS3 in S9 of Caco-2 Cells
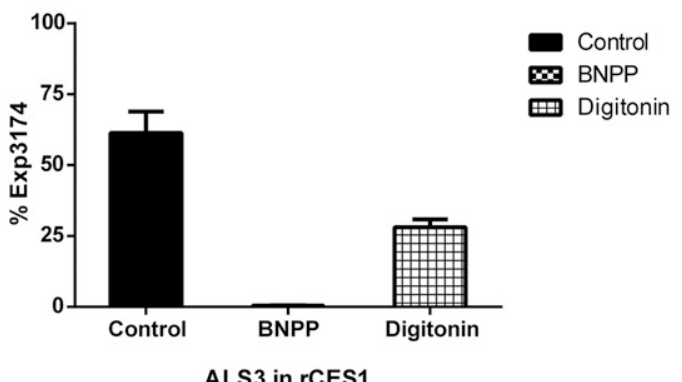

$\infty$ BNPP

표 Loperamide

$\mathbb{8}$ Eserine

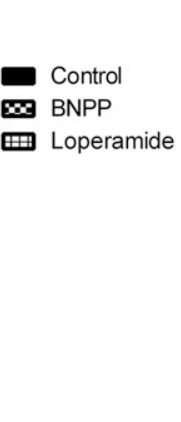

H

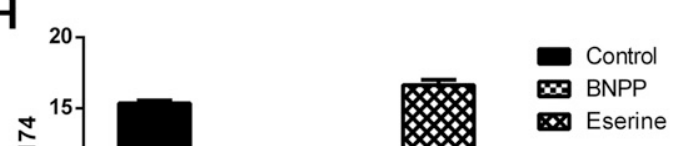

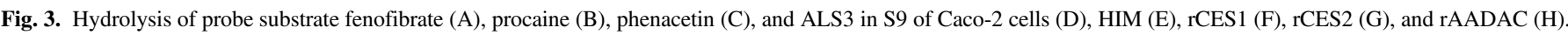

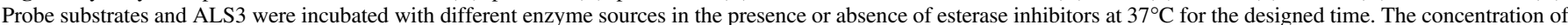

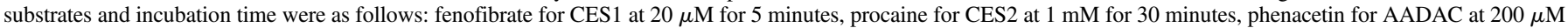

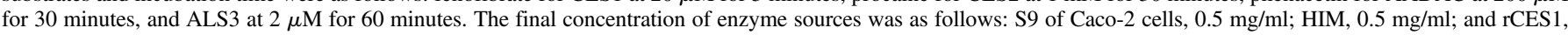

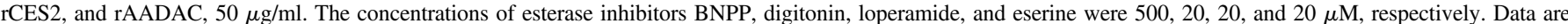
shown as the mean of duplicates.

ALS3 Hydrolysis In Vitro Incubations. ALS3 hydrolysis was incubated in various enzyme sources, including $\mathrm{S} 9$ of Caco- 2 cells, HIM, rCES1, rCES2, and rAADAC (Fig. 3). Fenofibrate, procaine, and phenacetin were investigated as the probe substrates of CES1, CES2, and AADAC in vitro enzyme incubations, respectively (Fig. 3, A-C). The results in Caco-2 S9 incubations showed that the response of fenofibrate hydrolysis metabolite was approximately 30-fold higher than that in PBS control and the nonspecific esterase inhibitor BNPP inhibited fenofibrate hydrolysis to the baseline level, whereas the response of hydrolysis metabolite of procaine and phenacetin was comparable to those in PBS control, indicating that CES1 is the predominate esterase in $\mathrm{S} 9$ of Caco- 2 cells, which is also confirmed by the immunoblot result (Supplemental Fig. 3). Similarly, the hydrolase activity of HIM, rCES1, rCES2, and rAADAC was confirmed based on the hydrolysis of probe substrates and the inhibition of inhibitors.

The percentage of Exp3174 in PBS control was $<1 \%$, indicating that ALS3 is stable in PBS for 60 minutes (data not shown). Almost completely hydrolysis of ALS3 to Exp3174 was observed in S9 of Caco2 cells in 60 minutes, and ALS3 hydrolase activity was efficiently inhibited by BNPP and digitonin (a specific inhibitor for CES1) to less than $50 \%$ and $70 \%$, respectively (Fig. 3D). Because CES1 is the main esterase in the S9 of Caco-2 cells, it was hypothesized that ALS3 is mainly hydrolyzed to Exp3174 in the S9 of Caco- 2 cells via CES1. 
Although CES1 is abundantly expressed in Caco-2 cells, CES2 and AADAC are the main esterases in human intestine. To investigate the esterase involved in ALS3 hydrolysis in humans, the hydrolysis of ALS3 in HIM, rCES1, rCES2, and rAADAC was further evaluated. Over 95\% of ALS3 was hydrolyzed to Exp3174 in HIM and rCES2 after 60-minute incubation, and the hydrolysis was markedly inhibited by BNPP and loperamide (a specific inhibitor for CES2) to different extents (Fig. 3, E and G). Approximately $61 \%$ of ALS3 was hydrolyzed to Exp3174 by rCES1, and inhibitors BNPP and digitonin could efficiently inhibit ALS3 hydrolysis (Fig. 3F). BNPP inhibited the ALS3 hydrolysis from $15 \%$ to $8 \%$ in rAADAC, but eserine (a specific inhibitor for AADAC) showed no inhibitory effect (Fig. $3 \mathrm{H}$ ). The lack of inhibition of eserine was supposed to be associated with its concentration used or the relative affinity of AADAC to ALS3 or eserine. Hydrolysis of ALS3 to Exp3174 in HIM, rCES1, and rCES2 all displayed sigmoidal autoactivation profiles based on the Eadie-Hofstee plots (Fig. 4). rCES1 exhibited a lower affinity for ALS3 hydrolysis to Exp3174 with $K_{\mathrm{m}}$ values of $14.5 \mu \mathrm{M}$ than that of HIM and rCES2, which exhibited comparable affinities for ALS3 hydrolysis to Exp3174 with $K_{\mathrm{m}}$ values of 6.92 and $6.77 \mu \mathrm{M}$, respectively (Fig. 4; Table 5). The intrinsic clearance of ALS3 in rCES2 was approximately 4 times higher than that in rCES1, indicating that CES2 is the predominant esterase in ALS3 hydrolysis to Exp3174 in humans.

Uptake of Exp3174 and ALS3 into OATP1A2- and OATP2B1Transfected HEK293 Cells. OATP1A2 and OATP2B1 are localized on the apical side of small intestine and are responsible for the uptake of many drugs into small intestine. The uptake of Exp3174 and ALS3 into OATP1A2- and OATP2B1-expressing HEK293 cells was investigated (Fig. 5). The uptake of Exp3174 in HEK293-OATP1A2 cells was comparable to that in Mock, whereas the accumulation of Exp3174 in HEK293-OATP2B1 cells was approximately 16.5-fold higher than that in HEK293-Mock cells, indicating that Exp3174 is a substrate of OATP2B1 other than OATP1A2 (Fig. 5A). For ALS3 uptake evaluation, ALS3 and Exp3174 were both detected in the cell lysate of HEK293 cells (data not shown). Considering the stability of ALS3 in HBSS, Exp3174 was hypothesized to be hydrolyzed by enzymes in HEK293 cells. Therefore, the sum of ALS3 and Exp3174 was used to evaluate the uptake of ALS3 in HEK293 cells. Similarly, the results suggested that ALS3 is the substrate of OATP2B1, not OATP1A2 (Fig. 5B). The concentration-dependent uptake assay of Exp3174 and ALS3 mediated by OATP2B1 was further evaluated. OATP2B1-mediated Exp3174 and ALS3 uptake both displayed sigmoidal autoactivation profiles based on the Eadie-Hofstee plots (Fig. 5, C and D). OATP2B1 exhibited lower affinities for Exp3174 than ALS3 (7.85 $\mu \mathrm{M}$ vs. $0.75 \mu \mathrm{M})$ with similar uptake rates, leading to a lower clearance of Exp3174 than ALS3 (16.1 pmol $/ \mathrm{min} / \mathrm{mg}$ vs. $215 \mathrm{pmol} / \mathrm{min} / \mathrm{mg}$ ) (Table 5), which indicated that ALS3 is preferred to be taken up by OATP2B1 into intestine epithelia.

Hydrolysis of ALS3 in CES2-Tranfected Caco-2 Cells and HEK293-OATP2B1 Cells. To investigate the interplay between transporters and CES2, the hydrolysis of ALS3 in CES2-transfected Caco-2 cells and HEK293-OATP2B1cells was evaluated. ALS3 and Exp3174 were both detected in the cell lysis of Caco-2 cells and HEK293 cells. Approximately 50\%-60\% of ALS3 was hydrolyzed to Exp3174 in Caco-2 cells with or without the transfection of CES2 (Fig. 6), indicating that the transfection of CES2 did not increase the hydrolysis of ALS3 to Exp3174 in Caco-2 cells. CES1 probe substrate fenofibrate and CES1specific inhibitor digitonin both showed little effects on the hydrolysis of ALS3 to Exp3174 in Caco-2 cells (data not shown). Different from Caco-2 cells, in HEK293-OATP2B1 cells the percentage of Exp3174 was highly elevated from approximately $30 \%$ to $55 \%$ in the presence of CES2, indicating that CES2 hydrolyzed ALS3 to Exp3174 after ALS3 was taken up into HEK293-OATP2B1 cells.

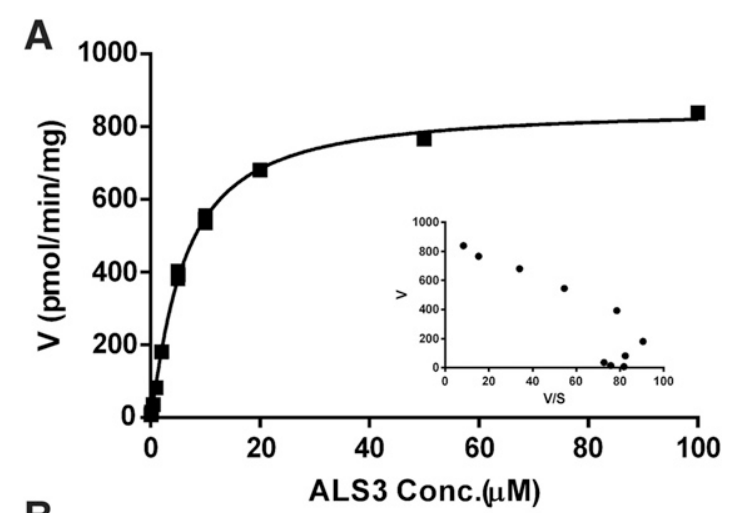

B
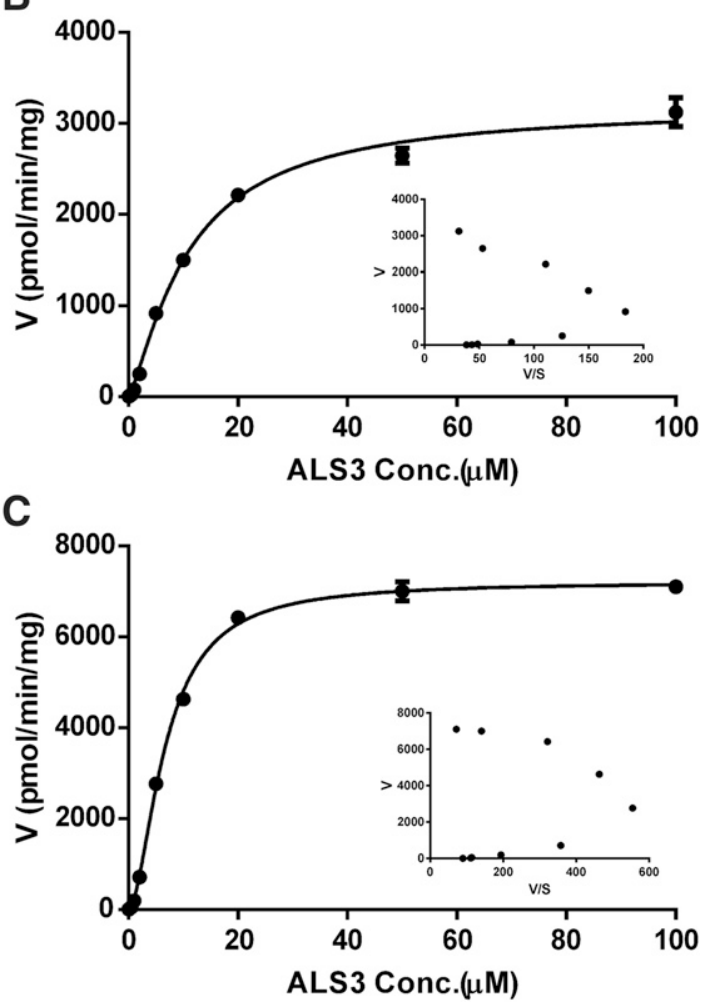

Fig. 4. Concentration-dependent hydrolysis of ALS3 to Exp3174 in HIM (A), rCES1 (B), and rCES2 (C). ALS3 ranging from 0.1 to $100 \mu \mathrm{M}$ was incubated with $0.1 \mathrm{mg} / \mathrm{ml}$ $\mathrm{HIM}$ for 10 minutes or incubated with $10 \mu \mathrm{g} / \mathrm{ml}$ rCES1 or rCES2 at $37^{\circ} \mathrm{C}$ for 20 minutes. The concentration of Exp3174 in incubation systems was determined for calculating the hydrolysis of ALS3. The concentration-dependent hydrolysis of ALS3 is also shown as the Eadie-Hofstee plots. Data are shown as the mean of replicates.

Expression of CES1 and CES2 in Caco-2 and HEK293OATP2B1 Cells. Reverse-transcription polymerase chain reaction (RT-PCR) was performed to evaluate the expression of CES mRNA in Caco-2 and HEK293-OATP2B1 cells. As shown in Table 6, CES2 mRNA expression in CES2-transfected Caco-2 cells and HEK293-OATP2B1 cells was 194 and 58.5 times higher than Caco-2 cells and HEK293OATP2B1 cells without CES2 transfection, respectively, indicating that CES2 was effectively transfected. Of note, the $\triangle \mathrm{Ct}$ value of CES1 mRNA was less than that of CES2 mRNA in CES2-transfected Caco-2 cells ( 0.65 vs. 2.96 , respectively), indicating that the expression of endogenous CES1 was much higher than the transfected CES2 in Caco- 2 cells.

\section{Discussion}

A prodrug ALS3 was designed to improve the oral bioavailability and reduce the variation of Exp3174, the active metabolite of losartan. 
TABLE 5

Kinetic parameters of hydrolysis and uptake of ALS3 and Exp3174 in vitro incubation systems

Data are shown as the mean $\pm S . D .(\mathrm{n}=2$ for hydrolysis assays and $\mathrm{n}=3$ for uptake assays).

\begin{tabular}{|c|c|c|c|c|c|c|}
\hline Type & Enzyme/Transporter & Kinetic Model & $K_{m}$ & $V_{\max }$ & $C L_{i n t}$ & $h$ \\
\hline & & & $\mu \mathrm{M}$ & $\mathrm{pmol} / \mathrm{min} / \mathrm{mg}$ & $\mu \mathrm{l} / \mathrm{min} / \mathrm{mg}$ & \\
\hline \multirow[t]{3}{*}{ ALS3 hydrolysis } & HIM & Michaelis-Menten $^{a}$ & $6.92 \pm 0.39$ & $895 \pm 14$ & $129 \pm 6$ & NA \\
\hline & CES1 & Michaelis-Menten $^{a}$ & $14.5 \pm 1.3$ & $3559 \pm 108$ & $245 \pm 17$ & NA \\
\hline & CES2 & Allosteric sigmoidal & $6.77 \pm 0.15$ & $7207 \pm 65$ & $1065 \pm 19$ & $1.77 \pm 0.06$ \\
\hline ALS3 uptake & OATP2B1 & Allosteric sigmoidal & $0.75 \pm 0.08$ & $182 \pm 9$ & $215 \pm 14$ & $1.72 \pm 0.23$ \\
\hline Exp3174 uptake & OATP2B1 & Allosteric sigmoidal & $7.85 \pm 0.33$ & $126 \pm 3$ & $16.1 \pm 0.5$ & $2.02 \pm 0.14$ \\
\hline
\end{tabular}

NA, not available.

${ }^{a}$ According to the Eadie-Hofstee plots in Fig. 4, the types of hydrolysis kinetics of ALS3 in HIM, rCES1, and rCES2 are all allosteric sigmoidal. However, the $h$ values for ALS3 in HIM and rCES1 were 1.18 and 1.28, respectively, which showed weak allosteric sigmoidal curves. By comparison of the two fits using GraphPad Prism software based on the $P$ value, Michaelis-Menten fit was chosen for calculating the kinetic parameters for HIM and rCES1. The $h$ value for ALS3 in rCES2 was 1.77 , and allosteric sigmoidal fit was thereby chosen based on the comparison of the two fits.

However, ALS3 exhibited even lower bioavailability than losartan in humans.

The low oral bioavailability of ALS3 was initially considered to be associated with its poor permeability. The permeability of ALS3 and active metabolite Exp3174 thereby was investigated using Caco-2 cells. The results indicated that Exp3174 has poor permeability with $\mathrm{P}_{\mathrm{app}}$ values of approximately $10^{-8} \mathrm{~cm} / \mathrm{s}$, and P-gp, BCRP, and MRP2 are involved in Exp3174 efflux. However, the lack of apparent efflux of Exp3174 in MDCK-MDR1, MDCK-BCRP, and MDCK-MRP2 cells suggested the opposite results from those in Caco-2 cells (data not shown). The different transport results from Caco-2 cells and MDCK cells for Exp3174 were also reported in the previous literature (Soldner

A

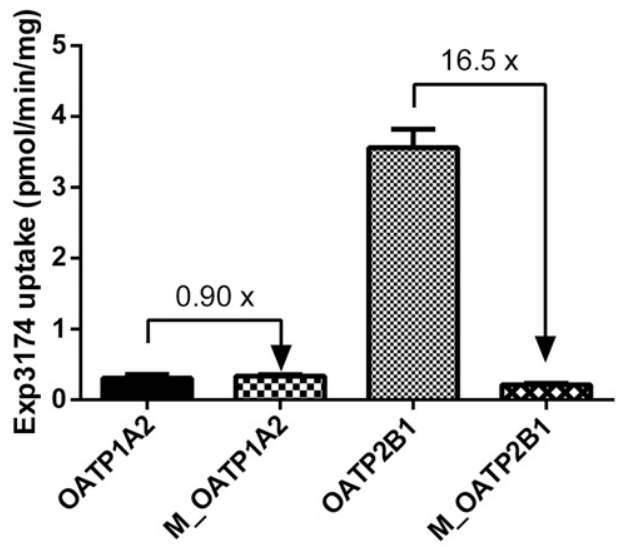

C

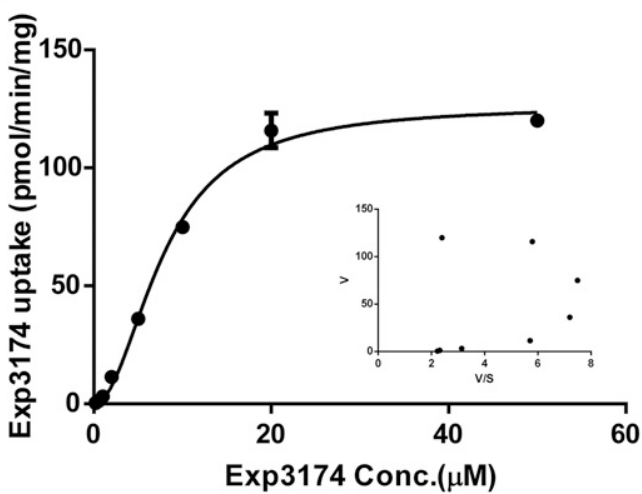

et al., 2000). To further identify whether Exp3174 was a substrate of efflux transporters, the uptake of Exp3174 into inside-out vesicles individually expressing P-gp, BCRP, and MRP2 was investigated, and the data confirmed that Exp3174 is a substrate of P-gp, BCRP, and MRP2. It is speculated that the differences between the data from MDCK cells and those from Caco- 2 cells or vesicles may be associated with the poor permeability of Exp3174 and the expression of a large variety of intestinal transporters in Caco- 2 cells. The poor permeability of Exp3174 makes it difficult to cross the apical and basolateral membrane, whereas the cooperation of multiple efflux transporters expressed in Caco- 2 cells may assist Exp3174 across the cell membrane and exhibit apparent active transport.

\section{B}

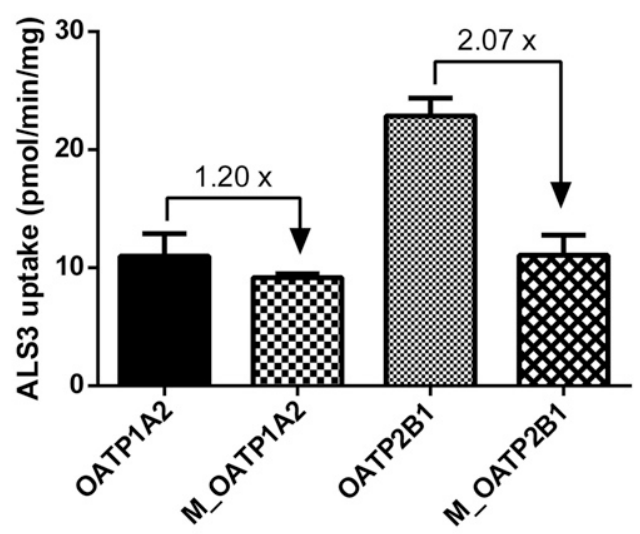

D

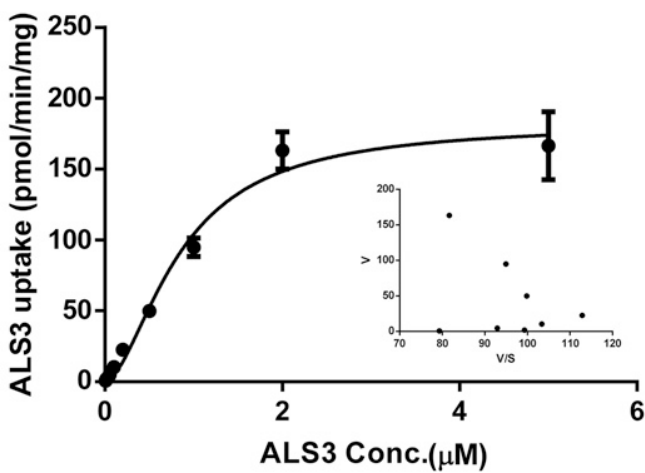

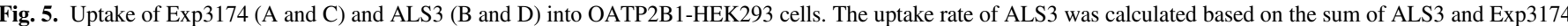

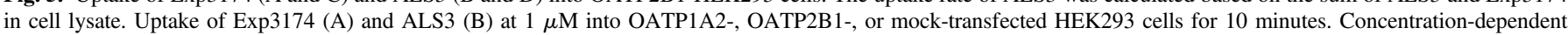

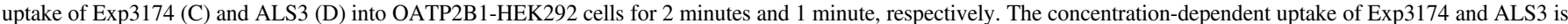
also shown as the Eadie-Hofstee plots. Data are shown as the mean \pm S.D. $(n=3)$. 

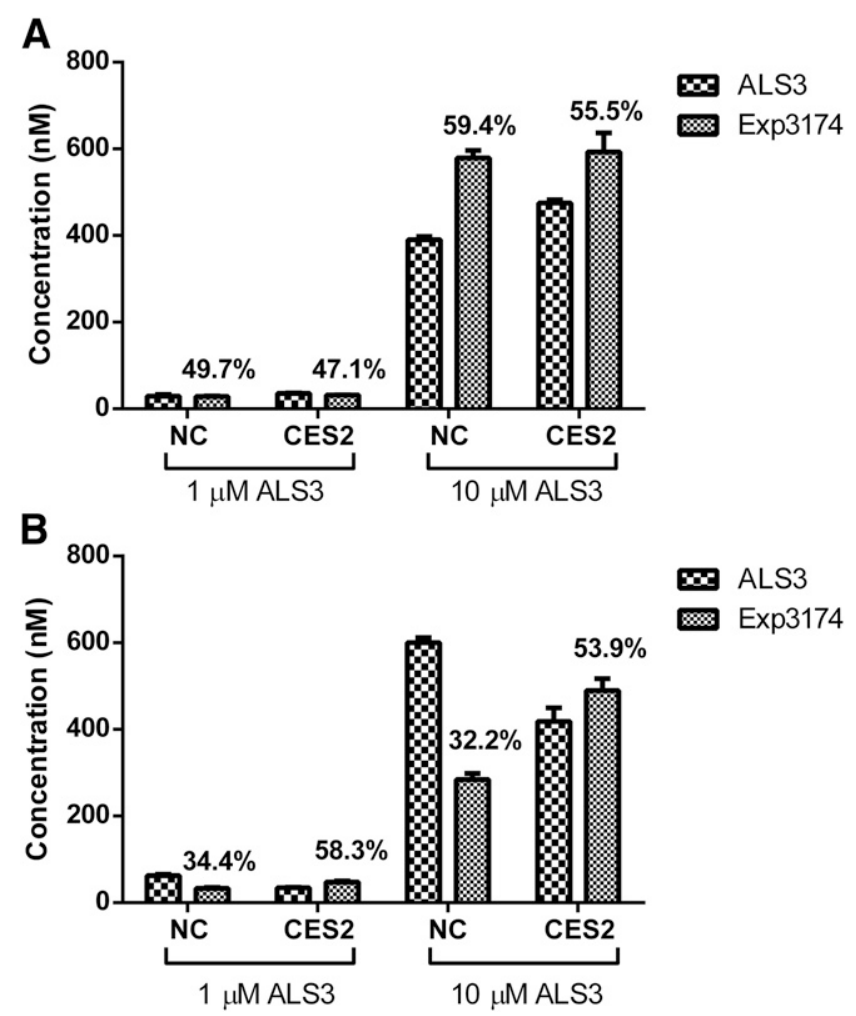

Fig. 6. Hydrolysis of ALS3 to Exp3174 in Caco-2 cells (A) and HEK293OATP2B1 cells (B) with or without CES2 transfection. ALS3 at 1 and $10 \mu \mathrm{M}$ was incubated with Caco-2 cells and HEK293-OATP2B1 cells for 5 minutes and 1 minute, respectively. The percentage numbers represent hydrolytic percentage of ALS3 in incubation systems. Bar labeled with "NC" represents the cells exposed to transfection reagents, but without plasmids, and bar labeled with "CES2" represents the cells transfected with CES2 plasmid. Data are shown as the mean \pm S.D. $(n=3)$.

Although ALS3 was stable in transport buffer without exposure to Caco- 2 cells for 2 hours, ALS3 was unexpectedly hardly detectable in receiver side after 2-hour bidirectional transport across Caco-2 cells, whereas high levels of Exp3174 in apical (donor or receiver) side were observed, and Exp3174 was also the predominant ALS3-related material in cell lysate (Table 3). All of these phenomena indicated that ALS3 is hydrolyzed to Exp3174 by enzymes in Caco-2 cells, and the produced Exp3174 is then transported by efflux transporters to the apical side. In addition, the concentration of Exp3174 in apical receiver side was approximately 14-20 times higher when ALS3 instead of Exp3174 was transported from B to A in Caco-2 cells (Tables 1 and 3), suggesting that ALS3 aided Exp3174 across Caco-2 cells, which may be attributed to the better permeability of ALS3 than Exp3174. And also, lower accumulation of Exp3174 in apical side for ALS3 from B to A transport than that of A to B transport indicated that uptake transporters on apical membrane facilitated the transport of ALS3 from apical chamber to Caco- 2 cells.
To confirm our hypothesis, the hydrolysis of ALS3 to Exp3174 and the transport of ALS3 were investigated in a variety of in vitro models. The hydrolysis of ALS3 was initially investigated in S9 of Caco-2 cells. ALS3 was almost completely hydrolyzed to Exp3174 in S9 of Caco-2 cells in 60 minutes, and the hydrolysis was inhibited by the nonspecific CES inhibitor BNPP. Only CES1 probe substrate fenofibrate was hydrolyzed in S9 of Caco-2 cells, indicating that CES1 is the predominant esterase in $\mathrm{S} 9$ of Caco-2 cells, which was consistent with the previous literature (Ohura et al., 2010, 2011), our RT-PCR results (Table 6), and Western blot results (Supplemental Fig. 3). It was thereby proposed that CES1 catalyzed ALS3 hydrolysis to Exp3174 in Caco-2 cells. In addition, we found that the hydrolysis of ALS3 to Exp3174 in S9 of Caco-2 cells decreased from approximately $93 \%$ to $40 \%$, with increasing ALS3 dosing concentrations from 2 to $50 \mu \mathrm{M}$ (data not shown), which was comparable to the percentage of Exp3174 in apical donor side in ALS3 transport from A to B in Caco-2 cells (Table 3), indicating that the hydrolysis of ALS3 at high concentrations is saturated by CES 1 in Caco- 2 cells.

It was reported that the major CES isozyme in human small intestine is CES2, whereas CES1 is predominantly expressed in Caco-2 cells and human liver (Imai et al., 2005; Ohura et al., 2010). Apart from CES1 and CES2, AADAC is also highly expressed in the liver and small intestine (Kobayashi et al., 2012; Fukami et al., 2015; Kurokawa et al., 2016; Jiang et al., 2017). To identify the major esterase isozymes responsible for ALS3 hydrolysis in humans, ALS3 hydrolase activity was assessed in well-functioned HIM, rCES1, rCES2, and rAADAC. ALS3 exhibited limited hydrolysis in rAADAC, but experienced extensive hydrolysis in HIM, rCES1, and rCES2 with $K_{\mathrm{m}}$ values of $6.92,14.5$, and $6.77 \mu \mathrm{M}$, respectively. The clearance (CL) value of ALS3 in rCES2 was approximately four times and eight times higher than those in rCES1 and HIM, respectively. Based on the tissue distribution of CES enzymes and the ALS3 hydrolysis, it was suggested that ALS3 is predominantly hydrolyzed to Exp3174 by CES2 in human small intestine.

Due to the extensive hydrolysis of ALS3 in Caco-2 cells, the permeability of ALS3 remained unclear. In MDCK suspension cells, approximately $50 \%$ of ALS3 could be hydrolyzed to Exp3174 at $37^{\circ} \mathrm{C}$ in 2 hours, and the Western blot results showed that CES1 was expressed in MDCK cells (Supplemental Fig. 3). But over 90\% of ALS3 existed in the donor side after a 2-hour incubation in transporter-expressing MDCK cell monolayers, which might be related to the cell density. Therefore, the permeability of ALS3 was identified in MDCK cells. The results showed that ALS has a low permeability with $\mathrm{P}_{\text {app }}$ values of approximately $3 \times 10^{-7} \mathrm{~cm} / \mathrm{s}$ in MDCK cells and is identified as the substrate of P-gp, BCRP, and MRP2.

Lower accumulation of Exp3174 in apical side for ALS3 B to A transport than that of A to B transport was observed in Caco-2 cells, which indicated that uptake transporters on apical membrane are involved in the transport of ALS3 from apical chamber to Caco- 2 cells. OATP1A2 and OATP2B1 are the main uptake transporters expressed on the apical membrane of intestine and are involved in multidrug intestinal

TABLE 6

mRNA expression of CES1 and CES2 in Caco-2 and HEK293-OATP2B1 cells

\begin{tabular}{|c|c|c|c|c|}
\hline \multirow{2}{*}{ Cells } & \multirow{2}{*}{ mRNA } & \multicolumn{2}{|c|}{$\Delta \mathrm{Ct}$ Values } & \multirow{2}{*}{ mRNA Ratio (B/A) } \\
\hline & & Nontransfected (A) & CES2-Transfected (B) & \\
\hline \multirow[t]{2}{*}{ Caco-2 } & CES1 & $0.78 \pm 0.15$ & $0.65 \pm 0.15$ & $1.09 \pm 0.01$ \\
\hline & CES2 & $10.5 \pm 0.2$ & $2.96 \pm 0.17$ & $194 \pm 29$ \\
\hline \multirow[t]{2}{*}{ HEK293-OATP2B1 } & CES1 & $12.0 \pm 0.6$ & $16.4 \pm 1.9$ & NA \\
\hline & CES2 & $8.27 \pm 0.06$ & $2.4 \pm 0.2$ & $58.5 \pm 7.6$ \\
\hline
\end{tabular}




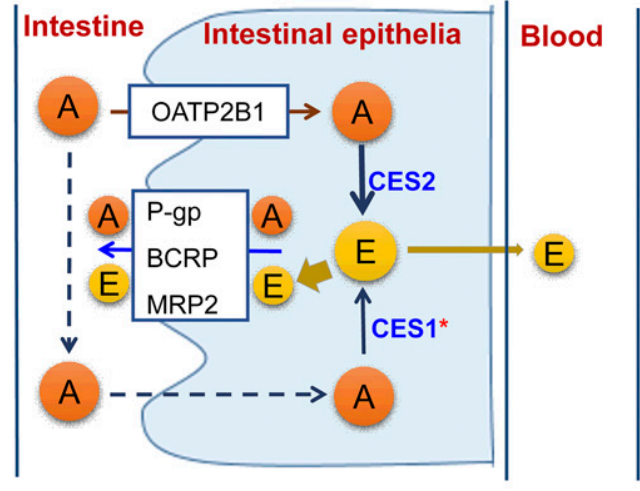

\section{A ALS3 E Exp3174}

\section{* in vitro Caco-2 cells}

Fig. 7. The proposed ALS3 disposition pathways in human intestine.

absorption (Shirasaka et al., 2010). In HEK293-OATP2B1 cells, the expression of endogenous CES1 and CES2 was demonstrated (Supplemental Fig. 3; Table 6), and approximately $30 \%$ of ALS3 was hydrolyzed to Exp3174. Our data suggested that Exp3174 and ALS3 are substrates of OATP2B1, but not OATP1A2. OATP2B1exhibited higher affinity and higher clearance toward ALS3 than Exp3174, with $K_{\mathrm{m}}$ values of 0.75 and $7.85 \mu \mathrm{M}$, respectively, indicating that ALS3 is preferred to be taken up into intestine epithelia.

The hydrolysis of ALS3 to Exp3174 was almost comparable in Caco2 cells with or without CES2 transfection, which was likely attributed to the much higher expression of endogenous CES1 than transfected CES2 based on RT-PCR results. As we expected, the hydrolysis of ALS3 in CES2-transfected HEK293-OATP2B1 cells was increased from approximately $30 \%$ to $55 \%$ (Fig. 6), indicating that CES2 hydrolyzed ALS3 to Exp3174 in HEK293-OATP2B1 cells. The hydrolysis of ALS3 in CES2-transfected HEK293-OATP2B1 cells provided supportive and indirect evidences for the possible interplay between OATP2B1 and CES2. Our results also suggested that Caco-2 cells are not particularly suitable for studying the interplay between OATP2B1 and CES2. However, it is technically difficult to construct in vitro models to highly express CES2, OATP2B1, and efflux transporters for determining the relative contributions of individual processes and the interplay to date.

Based on our study, ALS3 enters intestine epithelia mainly mediated by OATP2B1 and is then hydrolyzed to Exp3174 in intestine epithelia. ALS3 is the substrate of efflux transporters P-gp, BCRP, and MRP2; therefore, the in and out of ALS3 across intestine epithelia mediated by transporters may increase the potential of ALS3 hydrolysis to Exp3174, leading to undetectable ALS3 in circulation in humans. Considering that ALS3 is almost hydrolyzed to Exp3174 in intestine epithelia, the bioavailability of ALS3 is closely associated with Exp3174. Exp3174 is also a substrate of P-gp, BCRP, and MRP2, indicating that Exp3174 generated in intestine epithelia is predominately pumped to the intestine tract. In addition, Exp3174 exhibits poor permeability, and therefore, only a very small fraction could enter the circulation via passive diffusion, leading to a low bioavailability of ALS3. The proposed ALS3 disposition in vivo is shown in Fig. 7.

The design of prodrugs based on active compound has been a useful strategy in drug development to improve pharmacokinetic characteristics or reduce the toxicity in many successful cases, such as enalapril (prodrug of enalaprilat), prasugrel, and tenofovir alafenamide (prodrug of tenofovir) (Farid et al., 2010; Ray et al., 2016). However, in the case of ALS3, our results showed that ALS3 is quickly hydrolyzed to
Exp3174 in intestine by CES2, and the formed Exp3174 is predominately transported back to the gastrointestinal tract by efflux transporters, leading to a lower exposure of Exp3174 in circulation than that of losartan at the same dose in humans. Consequently, a prodrug that can avoid the hydrolysis by CES2 and AADAC in the intestine should be helpful to improve the bioavailability of Exp3174 in humans.

In summary, the present study demonstrated that ALS3 is taken up into intestinal epithelia by OATP2B1 and is then quickly hydrolyzed to Exp3174 by CES2 in intestinal epithelia. Both ALS3 and Exp3174 are substrates of efflux transporters P-gp, BCRP, and MRP2, leading to ALS3 and Exp3174 pumped backed to the gastrointestinal tract. The potential interplay between the CES2 hydrolysis and transporters in intestine contributes to the low bioavailability of ALS3 in humans. The findings in this study suggest that the ester prodrug should be rationally designed based on the characteristics of parent drug and the esterases.

\section{Acknowledgments}

We greatly appreciate Dr. Zhiwei Gao from Shanghai Institute of Materia Medica, Chinese Academy of Sciences (Shanghai, China) for helpful discussions.

\section{Authorship Contributions}

Participated in research design: $\mathrm{Li}$, Sun, Chen.

Conducted experiments: Li, Guo, Chen.

Contributed new reagents or analytic tools: Zhong, Chen.

Performed data analysis: Li, Chen.

Wrote or contributed to the writing of the manuscript: $\mathrm{Li}$, Chen.

\section{References}

Benet LZ, Cummins CL, and Wu CY (2003) Transporter-enzyme interactions: implications for predicting drug-drug interactions from in vitro data. Curr Drug Metab 4:393-398.

Benet LZ, Cummins CL, and Wu CY (2004) Unmasking the dynamic interplay between efflux transporters and metabolic enzymes. Int J Pharm 277:3-9.

Cummins CL, Salphati L, Reid MJ, and Benet LZ (2003) In vivo modulation of intestinal CYP3A metabolism by P-glycoprotein: studies using the rat single-pass intestinal perfusion model. J Pharmacol Exp Ther 305:306-314.

Farid NA, Kurihara A, and Wrighton SA (2010) Metabolism and disposition of the thienopyridine antiplatelet drugs ticlopidine, clopidogrel, and prasugrel in humans. J Clin Pharmacol 50: 126-142.

Fukami T, Kariya M, Kurokawa T, Iida A, and Nakajima M (2015) Comparison of substrate specificity among human arylacetamide deacetylase and carboxylesterases. Eur J Pharm Sci 78 : $47-53$.

Imai T, Imoto M, Sakamoto H, and Hashimoto M (2005) Identification of esterases expressed in Caco-2 cells and effects of their hydrolyzing activity in predicting human intestinal absorption. Drug Metab Dispos 33:1185-1190.

Jiang J, Chen X, and Zhong D (2017) Arylacetamide deacetylase is involved in vicagrel bioactivation in humans. Front Pharmacol 8:846.

Kobayashi Y, Fukami T, Nakajima A, Watanabe A, Nakajima M, and Yokoi T (2012) Species differences in tissue distribution and enzyme activities of arylacetamide deacetylase in human, rat, and mouse. Drug Metab Dispos 40:671-679.

Komura H and Iwaki M (2011) In vitro and in vivo small intestinal metabolism of CYP3A and UGT substrates in preclinical animals species and humans: species differences. Drug Metab Rev 43:476-498.

Kondo C, Onuki R, Kusuhara H, Suzuki H, Suzuki M, Okudaira N, Kojima M, Ishiwata K, Jonker JW, and Sugiyama Y (2005) Lack of improvement of oral absorption of ME3277 by prodrug formation is ascribed to the intestinal efflux mediated by breast cancer resistant protein (BCRP/ ABCG2). Pharm Res 22:613-618.

Kurokawa T, Fukami T, Yoshida T, and Nakajima M (2016) Arylacetamide deacetylase is responsible for activation of prasugrel in human and dog. Drug Metab Dispos 44:409-416.

Li C, Zhang L, Zhou L, Wo SK, Lin G, and Zuo Z (2012) Comparison of intestinal absorption and disposition of structurally similar bioactive flavones in Radix Scutellariae. AAPS J 14:23-34.

Li Y, Li XH, Huang ZJ, Yang GP, Zhang GG, Zhao SP, Guo Y, Lu SJ, Ma JL, Meng FB, et al. (2015) A randomized, double blind, placebo-controlled, multicenter phase II trial of Allisartan Isoproxil in essential hypertensive population at low-medium risk. PLoS One 10:e117560.

Lin X, Skolnik S, Chen X, and Wang J (2011) Attenuation of intestinal absorption by major efflux transporters: quantitative tools and strategies using a Caco-2 model. Drug Metab Dispos 39: 265-274.

Lo MW, Goldberg MR, McCrea JB, Lu H, Furtek CI, and Bjornsson TD (1995) Pharmacokinetics of losartan, an angiotensin II receptor antagonist, and its active metabolite EXP3174 in humans. Clin Pharmacol Ther 58:641-649.

Nauli AM and Nauli SM (2013) Intestinal transport as a potential determinant of drug bioavailability. Curr Clin Pharmacol 8:247-255.

Ohura K, Nozawa T, Murakami K, and Imai T (2011) Evaluation of transport mechanism of prodrugs and parent drugs formed by intracellular metabolism in Caco-2 cells with modified carboxylesterase activity: temocapril as a model case. J Pharm Sci 100:3985-3994.

Ohura K, Sakamoto H, Ninomiya S, and Imai T (2010) Development of a novel system for estimating human intestinal absorption using Caco-2 cells in the absence of esterase activity. Drug Metab Dispos 38:323-331. 
Poulter NR, Prabhakaran D, and Caulfield M (2015) Hypertension. Lancet 386:801-812.

Ray AS, Fordyce MW, and Hitchcock MJ (2016) Tenofovir alafenamide: a novel prodrug of tenofovir for the treatment of human immunodeficiency virus. Antiviral Res 125 $63-70$.

Rubio-Guerra AF and Duran-Salgado MB (2015) Recommendations for the treatment of hypertension in elderly people. Cardiovasc Hematol Agents Med Chem 12:146-151.

Shirasaka Y, Suzuki K, Nakanishi T, and Tamai I (2010) Intestinal absorption of HMG-CoA reductase inhibitor pravastatin mediated by organic anion transporting polypeptide. Pharm Res 27:2141-2149.

Soldner A, Benet LZ, Mutschler E, and Christians U (2000) Active transport of the angiotensin-II antagonist losartan and its main metabolite EXP 3174 across MDCK-MDR1 and caco-2 cell monolayers. Br J Pharmacol 129:1235-1243.

Stearns RA, Chakravarty PK, Chen R, and Chiu SHL (1995) Biotransformation of losartan to its active carboxylic acid metabolite in human liver microsomes: role of cytochrome P4502C and 3A subfamily members. Drug Metab Dispos 23:207-215.

Watanabe A, Fukami T, Nakajima M, Takamiya M, Aoki Y, and Yokoi T (2009) Human arylacetamide deacetylase is a principal enzyme in flutamide hydrolysis. Drug Metab Dispos 37: $1513-1520$.

Watanabe A, Fukami T, Takahashi S, Kobayashi Y, Nakagawa N, Nakajima M, and Yokoi T (2010) Arylacetamide deacetylase is a determinant enzyme for the difference in hydrolase activities of phenacetin and acetaminophen. Drug Metab Dispos 38: $1532-1537$

Wu CY and Benet LZ (2005) Predicting drug disposition via application of BCS: transport/ absorption/elimination interplay and development of a biopharmaceutics drug disposition classification system. Pharm Res 22:11-23.
Wu MY, Ma XJ, Yang C, Tao X, Liu AJ, Su DF, and Liu JG (2009) Effects of allisartan, a new AT(1) receptor blocker, on blood pressure and end-organ damage in hypertensive animals. Acta Pharmacol Sin 30:307-313.

Yang SH, Choi JS, and Choi DH (2011) Effects of HMG-CoA reductase inhibitors on the pharmacokinetics of losartan and its main metabolite EXP-3174 in rats: possible role of CYP3A4 and P-gp inhibition by HMG-CoA reductase inhibitors. Pharmacology 88:1-9.

Yasar U, Forslund-Bergengren C, Tybring G, Dorado P, Llerena A, Sjöqvist F, Eliasson E, and Dahl ML (2002) Pharmacokinetics of losartan and its metabolite E-3174 in relation to the CYP2C9 genotype. Clin Pharmacol Ther 71:89-98.

Yasar U, Tybring G, Hidestrand M, Oscarson M, Ingelman-Sundberg M, Dahl ML, and Eliasson E (2001) Role of CYP2C9 polymorphism in losartan oxidation. Drug Metab Dispos 29: 1051-1056.

Yun CH, Lee HS, Lee H, Rho JK, Jeong HG, and Guengerich FP (1995) Oxidation of the angiotensin II receptor antagonist losartan (DuP 753) in human liver microsomes: role of cytochrome P4503A(4) in formation of the active metabolite EXP3174. Drug Metab Dispos 23: $285-289$.

Zimmerman JJ (2004) Exposure-response relationships and drug interactions of sirolimus. AAPS J 6:e28

Address correspondence to: Dr. Xiaoyan Chen, Shanghai Institute of Materia Medica, Chinese Academy of Sciences, 501 Haike Road, Shanghai 201203, China. E-mail: xychen@simm.ac.cn 